\title{
Optimal Voltage-Support Control for Distributed Generation Inverters in RL Grid- Faulty Networks
}

\author{
Miguel Garnica, Luis García de Vicuña, Jaume Miret, Member, IEEE, Miguel Castilla, and \\ Ramón Guzmán
}

\begin{abstract}
During grid faults, the stability and reliability of the network are compromised, and the risk of a widespread disconnection of distributed generation power facilities is increased. Distributed generation inverters must support the power system to prevent this issue. Voltage support depends substantially on the currents injected into the grid and the equivalent grid impedance. This paper considers these two aspects and proposes an optimal voltage-support strategy in $R L$ grids. The control algorithm guarantees a safe operation of the inverter during voltage sags by calculating the appropriate reference currents according to the equivalent impedance and the voltage sag characteristics, avoiding active power oscillations, and limiting the injected current to the maximum allowed by the inverter. Consequently, the grid can be better supported since the voltage at the point of common coupling is improved and the voltage support objectives are achieved. The proposed control strategy is validated through experimental tests in different grid scenarios. Throughout the work, it is assumed that the grid impedance is known, but the proposed solution requires calculating the grid impedance angle.
\end{abstract}

Index Terms- Active power control, active power oscillation cancellation, distributed power generation, maximum current injection, reactive power control, unbalanced grid faults, voltage ride-through, voltage sag, voltage support.

Manuscript received December 14, 2018; revised April 25, 2019, June 26, 2019, and September 11, 2019; accepted October 03, 2019. This work was supported by the Ministry of Science, Innovation, and Universities of Spain and by the European Regional Development Fund under project RTI2018-100732-B-C22.

M. Garnica is with the Grupo de Investigación en Comunicación, Control y Diseño Naval, Escuela Naval de Cadetes "Almirante Padilla", Cartagena de Indias, D. T. y C. (Bolívar), Colombia, and with the Department of Electronic Engineering, Technical University of Catalonia, Barcelona, 08800, Spain (corresponding author: phone +57 300274 4873; e-mail: miguel.garnica@armada.mil.co).

L. García de Vicuña, J. Miret, and M. Castilla are with the Department of Electronic Engineering, Technical University of Catalonia, Barcelona, 08800, Spain (e-mail: vicuna@eel.upc.edu; jaume.miret@upc.edu; miquel.castilla@upc.edu).

R. Guzmán is with the Department of Automatic Control, Technical University of Catalonia, Barcelona, 08800, Spain (e-mail: ramon.guzman@upc.edu).

Color versions of one or more of the figures in this paper are available online at http://ieeexplore.ieee.org.

\section{NOMENCLATURE}

\section{GC Grid code.}

LVRT Low-voltage ride-through.

PCC Point of common coupling.

RCI Reactive current injection.

$Z_{g} \quad$ Grid impedance.

$\theta_{g} \quad$ Grid impedance angle.

$\theta_{i n j} \quad$ Injection angle.

$V^{+} \quad$ Positive-sequence voltage amplitude.

$V^{-} \quad$ Negative-sequence voltage amplitude.

$u \quad$ VUF, voltage unbalance factor.

$\varphi \quad$ Phase angle between positive and negative sequences.

$I_{\text {rated }} \quad$ Inverter rated current.

$I_{p}^{+} \quad$ Positive-sequence active current amplitude.

$I_{q}^{+} \quad$ Positive-sequence reactive current amplitude.

$I_{p \text { opt }}^{+}$Optimal $I_{p}^{+}$.

$I_{q \text { opt }}^{+}$Optimal $I_{q}^{+}$.

$I_{p}^{-} \quad$ Negative-sequence active current amplitude.

$I_{q}^{-} \quad$ Negative-sequence reactive current amplitude.

$P_{G} \quad$ Reference of generated active power.

$p, q \quad$ Instantaneous active/reactive power.

$\tilde{p}, \tilde{q} \quad$ Instantaneous active/reactive power oscillation.

\section{INTRODUCTION}

$\mathrm{T}$ HE growing number of distributed low-power generation systems connected to the grid [1] implies the need to guarantee the stability and reliability of the electrical network through the application of GCs that must be met to preserve the security of the electrical infrastructure, especially under fault conditions [2]-[4].

Voltage sags are the main power quality issue for process industries [5], and LVRT capability is the most important requirement to reduce disconnection risks of power facilities under fault conditions. This capability is related to situations 
in which the source must withstand the perturbation and operate continuously [6]. Regarding RCI capability for voltage support during grid faults, each GC indicates the amount of positive-sequence reactive current that will be injected as a function of the voltage at the PCC [7]-[10].

In recent years, many research works that address the control of grid-connected voltage-sourced inverters have focused on mainly inductive networks, but the actual grid impedance is not purely inductive. The line impedance consists of resistance, inductive reactance, and even capacitive reactance [11]. Most of these works are based on symmetrical components since they provide a practical tool for understanding the operation of a three-phase system under unbalanced conditions [12]. Different LVRT controllers are compared in [13], but they can only fulfill simultaneously with some of the proposed control objectives. Several strategies that try to improve the quality of the power delivered to the network can be found in [13]-[17]. Strategies focused on voltage support and reactive power injection are proposed in [18]-[20]. Control of maximum current to protect the inverter and avoid overcurrent tripping is led in studies such as [15][17], [21], [22]. New proposals considering only inductive grids, which include algorithms to maximize some power capabilities of inverters and inject active and reactive powers via positive and negative sequences, are introduced in [23][25], some of them achieve multiple control objectives.

Few works have been presented for mainly resistive networks, but strategies for this type of networks can be derived from the previous ones as evidenced in [26], where a flexible voltage support strategy in low-voltage grids is proposed.

Works considering networks with complex impedance are also limited. A voltage support strategy designed to increase as much as possible the positive-sequence voltage amplitude and to inject the rated current of the inverter is proposed in [27], although only simulation results are published. A zerosequence compensated voltage support scheme is proposed in [28], but the delivered active power presents oscillations under unbalanced voltage conditions. The control strategy implemented in [29] maximizes the voltage in the lowest phase and takes into account the impedance angle to generate the reference currents. However, the current is only injected by positive sequence and the active power oscillations are neither eliminated nor reduced. Three different voltage support strategies are proposed in [30], the first one only maximizes the amplitude of the positive-sequence voltage, the second one solely minimizes the amplitude of the negativesequence voltage, and the last strategy maximizes the difference between both magnitudes. However, none of these last three strategies eliminates or reduces the active power oscillations.

This paper presents a proposal of voltage support for lowpower rated grid-connected three-phase three-wire inverters during voltage sags, which optimizes current injection into the grid as a function of impedance angle while eliminating active power oscillations. This strategy provides a global solution to both LVRT requirements and optimal voltage support in $R L$

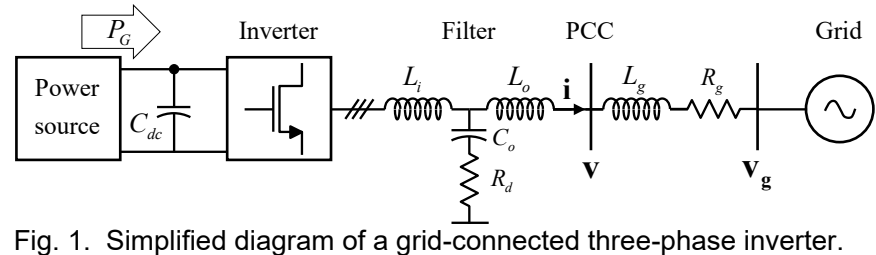

grids. By including impedance angle in the generation of reference currents, this proposal allows delivering active power and reactive power in an optimal way, which permits to exploit all network characteristics. Also, the injection of negative-sequence currents helps to reduce the voltage imbalance and to avoid active power oscillations. Therefore, the specific control objectives proposed in this work can be summarized as follow:

1) To reduce the voltage imbalance by maximizing the positive-sequence voltage amplitude and minimizing the negative-sequence voltage amplitude.

2) To limit the amount of injected current to the maximum allowed by the inverter during voltage sags.

3) To avoid active power oscillations.

Avoiding active power oscillations will reduce the ripple in the dc-link voltage, thus preventing from sudden disconnections of inverters due to violation of maximum/minimum voltage limits of the dc-link; besides, it favors the dc-link voltage control responsible for power injection optimization [14], [31]-[33]. In this context, this work aims to achieve the best control strategy for three-phase three-wire inverters connected to $R L$ grids during voltage sags. Hence, optimization of the voltage support, maximization of the current injected by the inverter, cancellation of the active power oscillations, and simultaneous achievement of these three control objectives will be the primary focus and the main contributions of the present study. The third objective has been proposed in many works, but it is the first time that is achieved for $R L$ grids within an algorithm with multiple goals. Note that this study presents a control scheme that works with any grid impedance, and the proposed solution requires knowing at least the network inductive/resistive ratio.

This paper is organized as follows. The system description is carried out in Section II. The proposed control strategy is developed and numerically validated in Section III. The experimental results are discussed in Section IV. Finally, Section $\mathrm{V}$ presents the conclusions and proposes some ideas for future work.

\section{SYSTEM DESCRIPTION}

In this section, the model of the grid-connected inverter, the three-phase voltage characterization under grid faults, and the complete control scheme are presented.

\section{A. Grid-Connected Three-Phase Three-Wire Inverter}

Fig. 1 shows a simplified diagram of a three-phase threewire inverter connected to the grid. The inverter is set in the power-controlled current source mode. An external controller provides the reference of generated active power $\left(P_{G}\right)$ that should be injected into the grid. A dc-link capacitor $C_{d c}$ 
operates the interconnection between the power source and the inverter to balance the power flow. The full-bridge inverter uses a damped $L C L$ filter to obtain a grid-side current with low harmonic content [34] and connects to the grid at the PCC, where the current and voltage vectors $(\mathbf{i}, \mathbf{v})$ are sensed. The grid is modeled as a voltage source $(\mathbf{v g})$ and an equivalent grid impedance $Z_{g}\left(R_{g}+j \omega L_{g}\right)$. It should be mentioned that for developing the control proposal, this impedance must be known. The knowledge of the nearby elements close to the facility or an online grid impedance estimator [35], [36] can be used for this purpose.

\section{B. Conventional Injection Under Grid Faults}

During voltage sags, the voltage vector ( $\mathbf{v})$ at the PCC can be described by their positive- and negative-symmetric sequences [37]. Applying Clarke's transformation, this local voltage is expressed in the stationary reference frame as

$$
\begin{aligned}
& v_{\alpha}=v_{\alpha}^{+}+v_{\alpha}^{-}=V^{+} \cos \left(\omega t+\varphi^{+}\right)+V^{-} \cos \left(\omega t+\varphi^{-}\right) \\
& v_{\beta}=v_{\beta}^{+}+v_{\beta}^{-}=V^{+} \sin \left(\omega t+\varphi^{+}\right)-V^{-} \sin \left(\omega t+\varphi^{-}\right)
\end{aligned}
$$

where $v_{\alpha}$ and $v_{\beta}$ are the $\alpha \beta$-frame components, $v_{\alpha}^{+}$and $v_{\beta}^{+}$ are the positive-sequence voltages, $v_{\alpha}^{-}$and $v_{\beta}^{-}$are the negative ones, and $\omega$ is the grid angular frequency. The difference between the initial phases $\left(\varphi^{+}\right.$and $\left.\varphi^{-}\right)$is called the phase angle $\varphi$. The complete solution to determine the angle $\varphi$ is obtained as [20]

$$
\begin{gathered}
\cos \varphi=\frac{v_{\alpha}^{+} v_{\alpha}^{-}-v_{\beta}^{+} v_{\beta}^{-}}{V^{+} V^{-}} \\
\sin \varphi=\frac{v_{\alpha}^{+} v_{\beta}^{-}+v_{\beta}^{+} v_{\alpha}^{-}}{V^{+} V^{-}} \\
\varphi=\operatorname{atan} 2(\sin \varphi, \cos \varphi)
\end{gathered}
$$

where atan2 is the two-argument arctangent function.

The voltage unbalance factor (VUF) is defined as the ratio of $V^{-}$to $V^{+}$[38]. Therefore:

$$
u=\frac{V^{-}}{V^{+}}=\frac{\sqrt{\left(v_{\alpha}^{-}\right)^{2}+\left(v_{\beta}^{-}\right)^{2}}}{\sqrt{\left(v_{\alpha}^{+}\right)^{2}+\left(v_{\beta}^{+}\right)^{2}}} .
$$

During no fault conditions, the main objective of a gridconnected inverter is to inject the generated active power into the grid. Thus it works as a power-controlled current source following the grid voltage [37]. When a voltage sag occurs, in order to support the grid, reactive power is injected to fulfill $\mathrm{GC}$ requirements. In this way, a generalized approach for gridconnected inverters to calculate the reference currents could be [23], [39]

$$
i_{\alpha}^{*}=I_{p}^{+}\left(\frac{v_{\alpha}^{+}}{V^{+}}\right)-I_{p}^{-}\left(\frac{v_{\alpha}^{-}}{V^{-}}\right)+I_{q}^{+}\left(\frac{v_{\beta}^{+}}{V^{+}}\right)+I_{q}^{-}\left(\frac{v_{\beta}^{-}}{V^{-}}\right)
$$

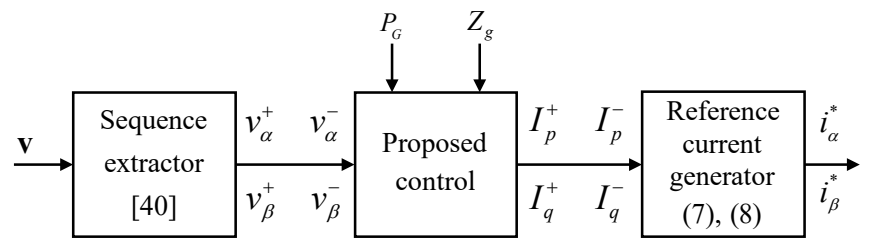

Fig. 2. Controller block diagram.

$$
i_{\beta}^{*}=I_{p}^{+}\left(\frac{v_{\beta}^{+}}{V^{+}}\right)-I_{p}^{-}\left(\frac{v_{\beta}^{-}}{V^{-}}\right)-I_{q}^{+}\left(\frac{v_{\alpha}^{+}}{V^{+}}\right)-I_{q}^{-}\left(\frac{v_{\alpha}^{-}}{V^{-}}\right)
$$

where $I_{p}^{+}$and $I_{p}^{-}$are the amplitudes of the positive- and negative-sequence active currents, respectively, and $I_{q}^{+}$and $I_{q}^{-}$are the reactive counterparts.

Note that during nominal conditions, only positive-sequence active power is injected into the grid through

$$
I_{p}^{+}=\frac{2}{3} \frac{V^{+}}{\left(V^{+}\right)^{2}-\left(V^{-}\right)^{2}} P_{G}
$$

where $V^{-}=0$ if there are no small voltage imbalances that can generate negative-sequence voltages under normal operation. Thus, in this condition, $I_{p}^{+}=\frac{2}{3} \frac{P_{G}}{V^{+}}$for the sake of simplicity.

On the other hand, during the sag, reactive power injection can be required; thus $I_{q}^{+}$must be calculated following these requirements [2], [3]. Commonly, $I_{p}^{-}$and $I_{q}^{-}$are set to zero to avoid current unbalancing. It must be pointed out that the scheme (7), (8) is a generalization of the conventional approaches to inject active $i_{p}$ and reactive $i_{q}$ currents for grid-feeding inverters.

\section{Control Scheme}

Fig. 2 displays the controller block diagram. The sensed voltage $\mathbf{v}$ is processed by a sequence extractor [40] to obtain the positive- and negative-sequence voltages. If the voltage sag threshold of the nominal or declared voltage is not surpassed, the reference currents $i_{\alpha}^{*}$ and $i_{\beta}^{*}$ are calculated with only positive-sequence active power (9). Once the sag is detected, the voltage support control is launched, and the GC requirements or other advanced control methods are used to calculate the amount of reactive power to be injected. In the proposal, as will be seen below, the grid impedance value is necessary for calculating the references of the active- and reactive-symmetric sequence currents. With the reference currents and the sensed currents $\mathrm{i}$, a proportional-resonant controller provides the duty cycles of the inverter.

\section{Optimal Voltage-Support Control Strategy WITH MAXIMUM CURRENT INJECTION}

This section formulates the control objectives and derives the expressions of the current amplitudes $I_{p}^{+}, I_{q}^{+}, I_{p}^{-}$, and $I_{q}^{-}$ that allow reaching the stated goals. The validity of these expressions is verified with a numerical example. 


\section{A. Control Objectives}

This work focuses on a new voltage support strategy in $R L$ grids with three control objectives that are fulfilled simultaneously when a voltage sag occurs. These objectives are:

1) To maximize the positive-sequence voltage amplitude and minimize the negative-sequence one,

$$
\max \left\{V^{+}\right\} \text {and } \min \left\{V^{-}\right\},
$$

to improve the voltage support capabilities of the inverter. The ideal situation of $V^{+}=1$ per unit (p.u.) and $V^{-}=0$ p.u. during the sag is not achieved in practice with lowpower rated inverters.

2) To limit the amount of injected current to the maximum allowed by the inverter,

$$
\max \left\{I_{a}, I_{b}, I_{c}\right\} \leq I_{\text {rated }},
$$

being $I_{a}, I_{b}$, and $I_{c}$ the amplitudes of the phase currents and $I_{\text {rated }}$ the maximum allowable inverter current. This objective is intended for protecting the inverter from overcurrents.

3) To avoid oscillations in the instantaneous active power $(p)$,

$$
p=P+\tilde{p}=P_{G}+0,
$$

where $\tilde{p}$ denotes the oscillating term of the active power.

\section{B. Optimal Voltage Support Strategy}

The instantaneous active and reactive powers that the inverter injects into the grid are defined as [41]

$$
\begin{aligned}
& p=\frac{3}{2}\left(v_{\alpha} i_{\alpha}+v_{\beta} i_{\beta}\right) \\
& q=\frac{3}{2}\left(v_{\beta} i_{\alpha}-v_{\alpha} i_{\beta}\right) .
\end{aligned}
$$

Thus substituting (1), (2), (7), and (8) into (13) and (14), the oscillating terms of the active and reactive powers can be derived as:

$$
\begin{aligned}
\tilde{p}= & \frac{3}{2} V^{+}\left(u I_{p}^{+}-I_{p}^{-}\right) \cos \left(2 \omega t+\varphi^{+}+\varphi^{-}\right) \\
& +\frac{3}{2} V^{+}\left(u I_{q}^{+}-I_{q}^{-}\right) \sin \left(2 \omega t+\varphi^{+}+\varphi^{-}\right) \\
\tilde{q}= & \frac{3}{2} V^{+}\left(u I_{q}^{+}+I_{q}^{-}\right) \cos \left(2 \omega t+\varphi^{+}+\varphi^{-}\right) \\
& -\frac{3}{2} V^{+}\left(u I_{p}^{+}+I_{p}^{-}\right) \sin \left(2 \omega t+\varphi^{+}+\varphi^{-}\right) .
\end{aligned}
$$

From (15) it can easily be seen that oscillations in instantaneous active power are zero if $I_{p}^{-}$and $I_{q}^{-}$are chosen as [23], [25], [39]

$$
\begin{aligned}
I_{p}^{-} & =u I_{p}^{+} \\
I_{q}^{-} & =u I_{q}^{+} .
\end{aligned}
$$

Thus the third objective will be fulfilled $(\tilde{p}=0)$. As can be seen, this goal has been reached with the drawback of unbalancing the injected currents. The positive point is that these currents are always sinusoidal signals. Also, it must be noted that reactive power oscillations will appear when using (17), (18) in (16).

On the other hand, based on Fig. 1, the instantaneous voltages at the PCC in the $\alpha \beta$ channels can be expressed as

$$
\begin{aligned}
& v_{\alpha}=R_{g} i_{\alpha}+L_{g} \frac{d i_{\alpha}}{d t}+v_{g \alpha} \\
& v_{\beta}=R_{g} i_{\beta}+L_{g} \frac{d i_{\beta}}{d t}+v_{g \beta}
\end{aligned}
$$

where $v_{g \alpha}$ and $v_{g \beta}$ are the sag voltages at the grid side, $R_{g}$ is the grid equivalent resistance, and $L_{g}$ is the grid equivalent inductance. Then, the amplitudes of the positive- and negative-sequence voltages at the PCC side can be obtained using (1), (2), (7), and (8) in (19) and (20) as follows [30]:

$$
\begin{aligned}
& V^{+} \approx V_{g}^{+}+R_{g} I_{p}^{+}+\omega L_{g} I_{q}^{+} \\
& V^{-} \approx V_{g}^{-}-R_{g} I_{p}^{-}-\omega L_{g} I_{q}^{-} .
\end{aligned}
$$

From (21) and (22), it can be settled that voltage support is related to the different amplitudes of the injected active and reactive currents. Hence, the main objective of this work can be clearly understood by analyzing these equations: positivesequence active and reactive currents help to increase positivesequence voltages $V^{+}$, and negative-sequence currents decrease negative-sequence voltages $V^{-}$. But the optimal solution is closely linked to the equivalent grid impedance. Accordingly, the impedance angle $\theta_{g}$ is chosen as the current injection angle $\theta_{i n j}$ :

$$
\theta_{i n j}=\theta_{g}=\tan ^{-1}\left(\frac{\omega L_{g}}{R_{g}}\right) .
$$

Therefore, the voltage support will be optimal if the current injection is made as a function of the chosen injection angle $\theta_{i n j}$, for which the amplitudes of the positive-sequence currents $I_{p}^{+}$and $I_{q}^{+}$will be defined based on the approach presented in [27] as

$$
I_{p}^{+}=I_{p \text { opt }}^{+}=I \cos \theta_{i n j} \quad ; \quad I_{q}^{+}=I_{q \text { opt }}^{+}=I \sin \theta_{i n j},
$$

where $I$ is the current amplitude value that will limit the inverter current to any predetermined value, as will be seen in Section III-C.

As can be seen, the relationships between positive- and negative-sequence currents (17), (18) determine the fulfillment of the third objective (related to power quality), and the relation between active and reactive currents (24) determines 
FUNC : OptimalVoltageSupport $\left(v_{\alpha}^{+}, v_{\beta}^{+}, v_{\alpha}^{-}, v_{\beta}^{-}, P_{G}, L_{g}, R_{g}\right)$

$$
\begin{aligned}
& 1 \quad \theta_{i n j}=\theta_{g}=\tan ^{-1}\left(\omega L_{g} / R_{g}\right) \\
& \text { /From known model or estimator }{ }^{*} / \\
& 2 V^{+}=\sqrt{\left(v_{\alpha}^{+}\right)^{2}+\left(v_{\beta}^{+}\right)^{2}} ; V^{-}=\sqrt{\left(v_{\alpha}^{-}\right)^{2}+\left(v_{\beta}^{-}\right)^{2}} ; u=\frac{V^{-}}{V^{+}} \\
& 3 \cos \varphi=\frac{v_{\alpha}^{+} v_{\alpha}^{-}-v_{\beta}^{+} v_{\beta}^{-}}{V^{+} V^{-}} ; \sin \varphi=\frac{v_{\alpha}^{+} v_{\beta}^{-}+v_{\beta}^{+} v_{\alpha}^{-}}{V^{+} V^{-}} \\
& 4 \varphi=\operatorname{atan} 2(\sin \varphi, \cos \varphi) \\
& 5 x=\min \left\{\cos (\varphi), \quad \cos \left(\varphi-\frac{2}{3} \pi\right), \cos \left(\varphi+\frac{2}{3} \pi\right)\right\} \\
& 6 \quad I=\frac{I_{\text {rated }}}{\sqrt{1-2 u x+u^{2}}} \\
& 7 I_{p}^{+}=\frac{2}{3} \frac{V^{+}}{\left(V^{+}\right)^{2}-\left(V^{-}\right)^{2}} P_{G} \quad \quad I^{*} \text { Calculate } I_{p}^{+} \text {from } P_{G}^{*} / \\
& 8 I_{q}^{+}=\sqrt{\frac{I_{\text {rated }}^{2}}{1-2 u x+u^{2}}-\left(I_{p}^{+}\right)^{2}} \quad \text { /*Calculate } I_{q}^{+*} / \\
& 9 I_{p \text { opt }}^{+}=I \cos \theta_{i n j} ; I_{q \text { opt }}^{+}=I \sin \theta_{i n j} \quad /^{*} \text { Calculate optimal values }{ }^{*} / \\
& 10 \text { if } I_{p}^{+} \geq I_{p \text { opt }}^{+} \text {then } \\
& 11 \quad\left\llcorner I_{p}^{+}=I_{p \text { opt }}^{+} ; I_{q}^{+}=I_{q \text { opt }}^{+} \quad \text { /*Optimal solution }{ }^{*} /\right. \\
& 12 I_{p}^{-}=u I_{p}^{+} ; I_{q}^{-}=u I_{q}^{+} \\
& 13 i_{\alpha}^{*}=I_{p}^{+}\left(\frac{v_{\alpha}^{+}}{V^{+}}\right)-I_{p}^{-}\left(\frac{v_{\alpha}^{-}}{V^{-}}\right)+I_{q}^{+}\left(\frac{v_{\beta}^{+}}{V^{+}}\right)+I_{q}^{-}\left(\frac{v_{\beta}^{-}}{V^{-}}\right) \\
& 14 i_{\beta}^{*}=I_{p}^{+}\left(\frac{v_{\beta}^{+}}{V^{+}}\right)-I_{p}^{-}\left(\frac{v_{\beta}^{-}}{V^{-}}\right)-I_{q}^{+}\left(\frac{v_{\alpha}^{+}}{V^{+}}\right)-I_{q}^{-}\left(\frac{v_{\alpha}^{-}}{V^{-}}\right)
\end{aligned}
$$

Fig. 3. Pseudocode for the controller implementation of the proposed voltage support strategy.

the accomplishment of the first objective: optimal voltage support.

Now, using (24) in (21) and (22), the amplitudes of the positive- and negative-sequence voltages can be written as

$$
\begin{aligned}
& V^{+}=V_{g}^{+}+I \sqrt{R_{g}^{2}+\left(\omega L_{g}\right)^{2}} \\
& V^{-}=V_{g}^{-}-u I \sqrt{R_{g}^{2}+\left(\omega L_{g}\right)^{2}} .
\end{aligned}
$$

\section{Limitation of the Phase Current Amplitudes}

Assuming that the injected currents follow their references, $i \approx i^{*}$, the phase current amplitudes can be calculated by applying the inverse Clarke's transformation to (7) and (8) using (17) and (18). The resulting phase amplitudes are a function of the voltage sag characteristics and the magnitudes of $I_{p}^{+}$and $I_{q}^{+}$(see [27], [29], [30] for further details):

$$
\begin{gathered}
I_{a}=\sqrt{\left(1-2 u \cos (\varphi)+u^{2}\right)\left(\left(I_{p}^{+}\right)^{2}+\left(I_{q}^{+}\right)^{2}\right)} \\
I_{b}=\sqrt{\left(1-2 u \cos \left(\varphi-\frac{2 \pi}{3}\right)+u^{2}\right)\left(\left(I_{p}^{+}\right)^{2}+\left(I_{q}^{+}\right)^{2}\right)} \\
I_{c}=\sqrt{\left(1-2 u \cos \left(\varphi+\frac{2 \pi}{3}\right)+u^{2}\right)\left(\left(I_{p}^{+}\right)^{2}+\left(I_{q}^{+}\right)^{2}\right)} .
\end{gathered}
$$

According to (27)-(29), the phase with the maximum current amplitude is related to the minimum value of the corresponding cosine function

$$
x=\min \left\{\cos (\varphi), \quad \cos \left(\varphi-\frac{2 \pi}{3}\right), \quad \cos \left(\varphi+\frac{2 \pi}{3}\right)\right\} .
$$

Therefore, the phase current maximum amplitude $\left(I_{\max }\right)$ can be determined as through the following expression:

$$
I_{\max }=\sqrt{1-2 u x+u^{2}} \sqrt{\left(I_{p}^{+}\right)^{2}+\left(I_{q}^{+}\right)^{2}} .
$$

Consequently, $I_{\max }$ is the maximum current that the inverter can inject to avoid damages or its disconnection due to overcurrent. Besides, it must be fulfilled that $I_{\max } \leq I_{\text {rated }}$. Finally, $I$ can be determined by using (24) and $I_{\max }=I_{\text {rated }}$ in (31) as

$$
I_{\text {rated }}=\sqrt{1-2 u x+u^{2}} \sqrt{I^{2}\left(\cos ^{2} \theta_{i n j}+\sin ^{2} \theta_{i n j}\right)}
$$

and solving the resulting expression for the amplitude $I$ :

$$
I=\frac{I_{\text {rated }}}{\sqrt{1-2 u x+u^{2}}} .
$$

The previous development makes possible both optimal voltage support and maximum current injection without oscillations of active power for any grid impedance and constitutes the main contribution of this work. It is worth to point out that using this controller implies that active power curtailment will be done to prioritize optimal voltage support over active power injection. Note that $P_{G}$ has not been used in the proposed optimal control.

Fig. 3 shows the pseudocode of the algorithm that implements the control at run-time. It should be noted that if the power generated by the source is low and the optimal value $I_{p \text { opt }}^{+}$cannot be reached, then $I_{p}^{+}$will be calculated based on $P_{G}$ (9). Additionally, $I_{q}^{+}$will be recalculated to inject the maximum current of the inverter:

$$
I_{q}^{+}=\sqrt{\frac{I_{\text {rated }}^{2}}{1-2 u x+u^{2}}-\left(I_{p}^{+}\right)^{2}} .
$$

Under these conditions (low-power production scenario), the negative sequence components of the active and reactive currents are calculated according to (17) and (18), canceling oscillations of the active power, and the output current of the inverter is also suitably limited, but the provided voltage support would not be optimal.

On the other hand, also note a current amplitude (symmetric sequence currents) approach instead of a reference power approach has been developed to ensure peak current limitation. In high-power production scenarios, the power curtailment will be based on the comparison between $I_{p}^{+}$and $I_{p \text { opt }}^{+}$. In fact, the latter will become the reference that implies the amount of active power that will be delivered to the network. 
TABLE I

SYSTEM PARAMETERS

\begin{tabular}{clrl}
\hline \hline \multirow{2}{*}{ Symbol } & \multicolumn{1}{c}{ Quantity } & Nominal value \\
\hline$V$ & grid voltage & 110.0 & $\mathrm{~V} \mathrm{rms}$ \\
$f$ & nominal grid frequency & 60.0 & $\mathrm{~Hz}$ \\
$L_{g}$ & equivalent grid inductance & 5.0 & $\mathrm{mH}$ \\
$R_{g}$ & equivalent grid resistance & 1.0 & $\Omega$ \\
$S_{b}$ & rated power & 2.3 & $\mathrm{kVA}$ \\
$I_{r a t e d}$ & rated current amplitude & 6.0 & $\mathrm{~A}$ \\
$V_{d c}$ & dc-link voltage & 360.0 & $\mathrm{~V}$ \\
$C_{d c}$ & dc-link capacitor & 1.0 & $\mathrm{mF}$ \\
$L_{i}$ & $L C L$ inverter-side inductances & 5.0 & $\mathrm{mH}$ \\
$C_{o}$ & $L C L$ filter capacitors & 2.0 & $\mu \mathrm{F}$ \\
$R_{d}$ & $L C L$ damping resistors & 68.0 & $\Omega$ \\
$L_{o}$ & $L C L$ output-side inductances & 2.0 & $\mathrm{mH}$ \\
$f_{s}$ & sampling, switching frequency & 10.0 & $\mathrm{kHz}$ \\
\hline \hline
\end{tabular}

\section{Numerical Validation}

As an example, suppose a $155 \mathrm{~V}$ (1-n, peak), $60 \mathrm{~Hz}$ electric power system with an equivalent line impedance $Z_{g}=1.0+$ j1.885 $\Omega$ where an unbalanced voltage sag occurs with the following characteristics: $V_{g}^{+}=101.12 \mathrm{~V}, V_{g}^{-}=17.11 \mathrm{~V}$, and $\varphi=146^{\circ}$. The active power production is $P_{G}=750 \mathrm{~W}$, and the maximum current of the inverter is $I_{\max }=6 \mathrm{~A}$. Table I shows the nominal values of the system parameters.

Thus, by substituting the previous data in the corresponding expressions, it is possible to calculate the amplitudes of the positive- and negative-sequence currents [see (17), (18), (24), and (33)], as well as the amplitudes of the phase currents [see (27)-(29)]. As expected, the results obtained through (25) and (26) show the remarkable performance of the voltage support strategy. Table II presents the results of these computations.

Note that $\theta_{g}=\theta_{i n j}^{+}=\theta_{i n j}^{-}=62.05^{\circ}$ :

$$
\theta_{g}=\tan ^{-1}\left(\frac{\omega L_{g}}{R_{g}}\right)=\tan ^{-1}\left(\frac{I_{q}^{+}}{I_{p}^{+}}\right)=\tan ^{-1}\left(\frac{I_{q}^{-}}{I_{p}^{-}}\right) .
$$

Likewise, (25) and (26) are represented graphically in Fig. 4 when the injection angle $\theta_{i n j}$ changes from $0^{\circ}$ to $90^{\circ}$. As can be seen, only when the injection angle $\theta_{i n j}$ coincides with the grid impedance angle $\theta_{g}$, the voltage support in $R L$ networks is optimal, $62.05^{\circ}$ in this example. The dashed red vertical lines mark both the maximum value of $V^{+}$and the minimum value of $V^{-}$.

\section{EXPERIMENTAL VALIDATION}

This section validates the theoretical contributions of this work by presenting the obtained experimental results. Four main sets of tests were carried out to confirm the performance of the proposed control scheme and to demonstrate the simultaneous fulfillment of the control objectives.
TABLE II

RESULTS OF THE NUMERICAL VALIDATION

\begin{tabular}{clrl}
\hline \hline Symbol & \multicolumn{1}{c}{ Quantity } & Nominal value \\
\hline$I_{p}^{+}$ & positive-sequence active current & 2.46 & $\mathrm{~A}$ \\
$I_{p}^{-}$ & negative-sequence active current & 0.42 & $\mathrm{~A}$ \\
$I_{q}^{+}$ & positive-sequence reactive current & 4.63 & $\mathrm{~A}$ \\
$I_{q}^{-}$ & negative-sequence reactive current & 0.78 & $\mathrm{~A}$ \\
$I_{a}$ & peak current of phase $a$ & 6.00 & $\mathrm{~A}$ \\
$I_{b}$ & peak current of phase $b$ & 4.46 & $\mathrm{~A}$ \\
$I_{c}$ & peak current of phase $c$ & 5.38 & $\mathrm{~A}$ \\
$V^{+}$ & positive-sequence voltage amplitude & 112.31 & $\mathrm{~V}$ \\
$V^{-}$ & negative-sequence voltage amplitude & 15.22 & $\mathrm{~V}$ \\
$\theta_{g}$ & grid impedance angle & 62.05 & $\mathrm{deg}$ \\
$\theta_{i n j}^{+}$ & injection angle of positive sequences & 62.05 & $\mathrm{deg}$ \\
$\theta_{i n j}^{-}$ & injection angle of negative sequences & 62.05 & $\mathrm{deg}$ \\
\hline \hline
\end{tabular}

\section{A. Experimental Setup}

Based on Fig. 1, an experimental prototype rated at $2.3 \mathrm{kVA}$ was built using a Guasch MTL-CBI0060F12IXHF full-bridge converter with an $L C L$ filter for harmonic reduction [34]. The controller has been implemented on a Texas Instruments F28M36 floating point DSP. The grid has been emulated using a programmable three-phase Pacific AMX-360 AC source, and the DG source behavior has been obtained through an AMREL SPS800-12-D013 DC source. The sequence extractor was implemented using second-order generalized integrators (SOGI) [40] with a time response of $16 \mathrm{~ms}$. The current loops incorporate proportional-resonant (PRes) controllers [42] tuned at the grid frequency. Total execution time is approximately $25 \%$ of the sampling time $(100 \mu \mathrm{s})$. Table I shows the main parameter values of the testbed.

Fig. 5(a) shows the voltage sag under test when there is no injection and the control is not activated. Near $t=0 \mathrm{~s}$, the voltages are almost balanced and at 1 p.u. The voltage sag occurs from $t=0.084 \mathrm{~s}$ to $t=0.384 \mathrm{~s}$. Before and after the sag, the inverter operates in normal mode. Fig. 5(b) displays the positive- and negative-sequence voltage amplitudes during the sag: $V^{+}=0.65$ p.u. and $V^{-}=0.11$ p.u. The sag has been chosen because it presents an imbalance and a large reduction in the positive-sequence voltage ( 0.65 p.u.). Fig. 5(c) depicts

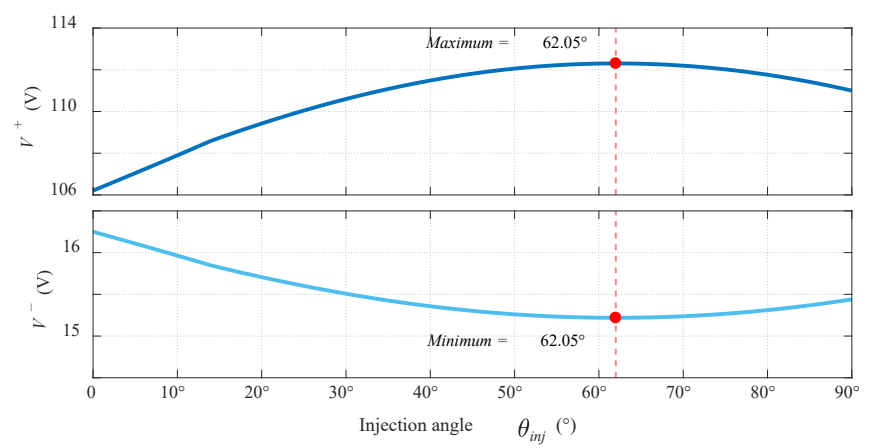

Fig. 4. Voltage support of $V^{+}$and $V^{-}$as a function of the injection angle. 

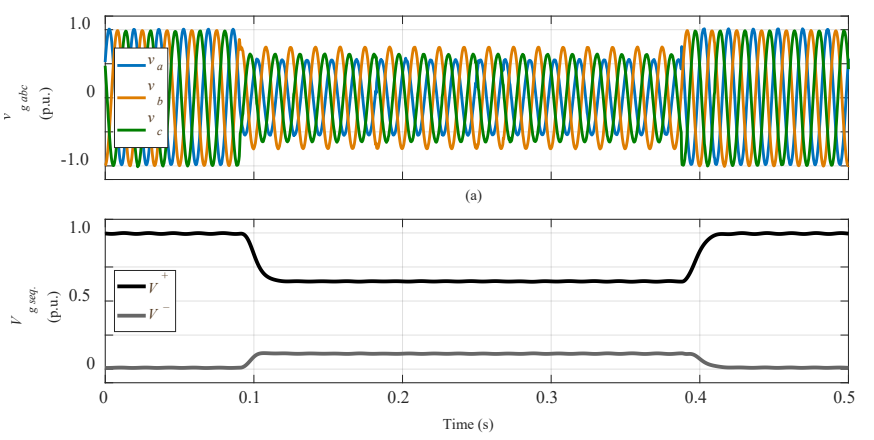

(b)

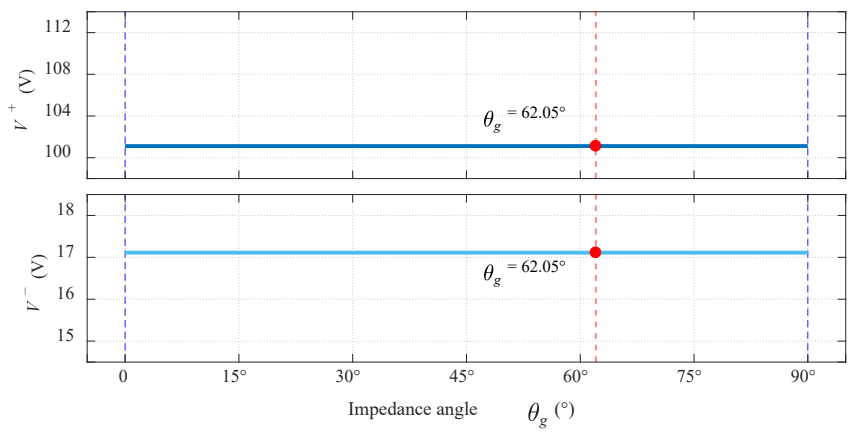

(c)

Fig. 5. Voltage sag under test without voltage support. (a) Phase voltages. (b) Voltage sequences. (c) $V^{+}$and $V$ - without current injection, and grid impedance angle.

out the values of the positive and negative-sequence voltages and highlights the grid impedance angle. Thus without injection $V^{+} \approx 101.12 \mathrm{~V}$ and $V^{-} \approx 17.11 \mathrm{~V}$.

Four different scenarios have been chosen to demonstrate the effectiveness of the control proposal in diverse grid conditions. Therefore, three distinct grid impedances have been considered: 1) $Z_{g}=1.0+\mathrm{j} 1.885 \Omega$, mainly inductive grid impedance; 2) $Z_{g}=0.1+\mathrm{j} 1.885 \Omega$, almost purely inductive grid impedance; and 3) $Z_{g}=4.0+\mathrm{j} 1.885 \Omega$, mainly resistive grid impedance.

\section{B. Scenario 1. Mainly Inductive RL Grid-High Active Power Production}

In this first test, the grid impedance is mainly inductive but with a non-negligible resistive part, $Z_{g}=1.0+\mathrm{j} 1.885 \Omega$. The voltage sag is detected at $t=0.1 \mathrm{~s}$ (when $V^{+}$is at 0.85 p.u.), i.e., one grid period after the start of the sag at $t=0.084 \mathrm{~s}$ due to the delay of the SOGI sequence extractor. Before the sag, the inverter is injecting $P_{G}=750 \mathrm{~W}$ through positive sequence $I_{p}^{+}$.

Once the sag is detected, the proposed controller is enabled. Fig. 6(a) shows the instantaneous phase voltages. Fig. 6(b) shows the positive- and negative-sequence voltage amplitudes, where a clear increment on $V^{+}(0.72$ p.u.) and a decrement in $V^{-}(0.10$ p.u.) can be observed concerning Fig. 5(b). It can be noted that the amplitude of the positive-sequence voltage has been increased but is still far from the normal operation boundary (i.e., 0.85 p.u. in [8]). It must be pointed out again that the proposal is intended for low-power rated distributed generators, which do not have enough power capacity to bring the system to a complete voltage recovery during the sag. Fig. 6(c) confirms that when the injection angle matches the
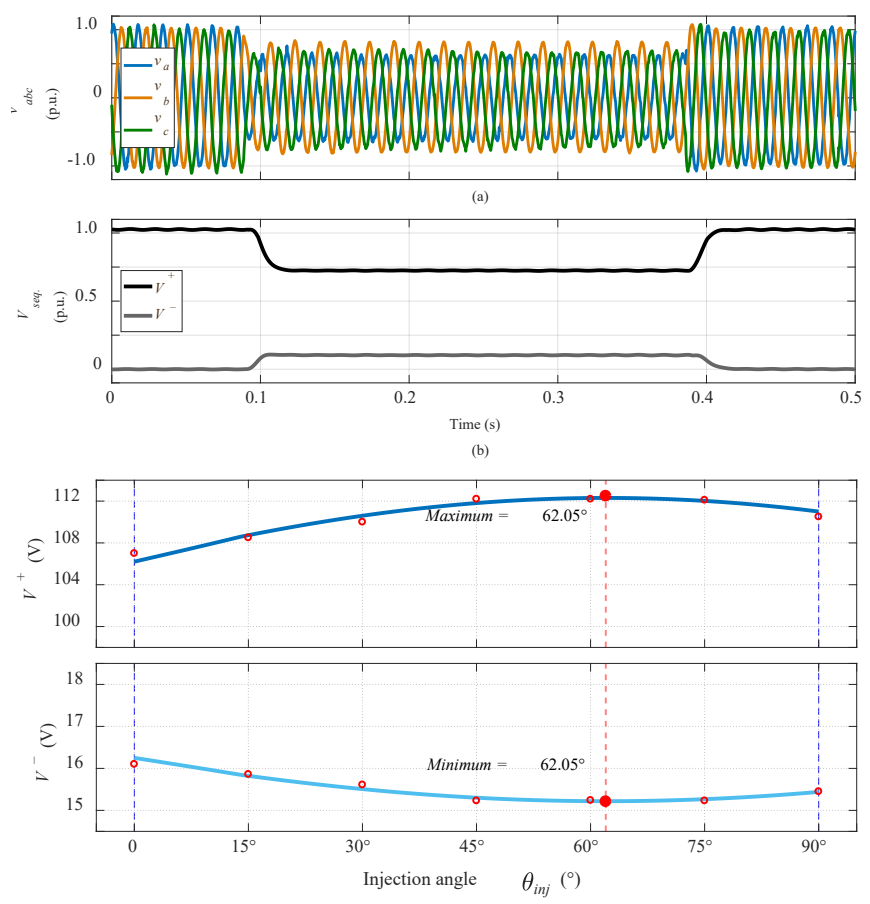

(c)

Fig. 6. Test in a mainly inductive $R L$ grid, $P_{G}=750 \mathrm{~W}$. (a) Phase voltages. (b) Voltage sequences. (c) $V^{+}$and $V^{-}$under impedance matching and injection angle.

impedance angle, the voltage support in $R L$ grids is optimal. The red circular markers represent several tests performed using different injection angles $\left(\left[0^{\circ}: 15^{\circ}: 90^{\circ}\right]\right)$. The voltage support results agree with the theoretical values obtained according to (25) and (26). Also, it can be clearly seen that the optimal solution lies in the grid impedance angle (i.e., the objective 1 is fulfilled).

However, the experimental tests presented in Fig. 6(c) show that an estimated value of the grid impedance, close to the real value, allows obtaining a valid calculation of the solution. The performed experiments show that an accurately calculated grid impedance is not necessary since voltage variations are small within the range of grid impedance values around the actual value. Besides, actual power system parameters change dynamically, which would generate differences between real and estimated grid impedances [29].

Fig. 7(a) shows the instantaneous phase currents injected by the inverter. Before and after the fault, the inverter injects balanced currents, i.e., $i_{a b c} \approx 0.5$ p.u. $(3 \mathrm{~A})$. As can be seen, the injected currents never exceed $I_{\text {rated }}=I_{\max }=1$ p.u. $(6 \mathrm{~A})$, which guarantees a safe current injection during the fault (i.e., the objective 2 is fulfilled). Fig. 7(b) displays the amplitudes of the positive- and negative-sequence active and reactive currents. During normal operation, only $I_{p}^{+}$is injected. Note that when the voltage disturbance begins, and the sag has not yet detected, the inverter tries to maintain the pre-fault power delivery, increasing $I_{p}^{+}$slightly. However, when the proposed algorithm is activated, $I_{p}^{+}$is reduced to favor the reactive current injection (active power curtailment). Then, simultaneously appears $I_{p}^{-} \neq 0$ to eliminate active power 

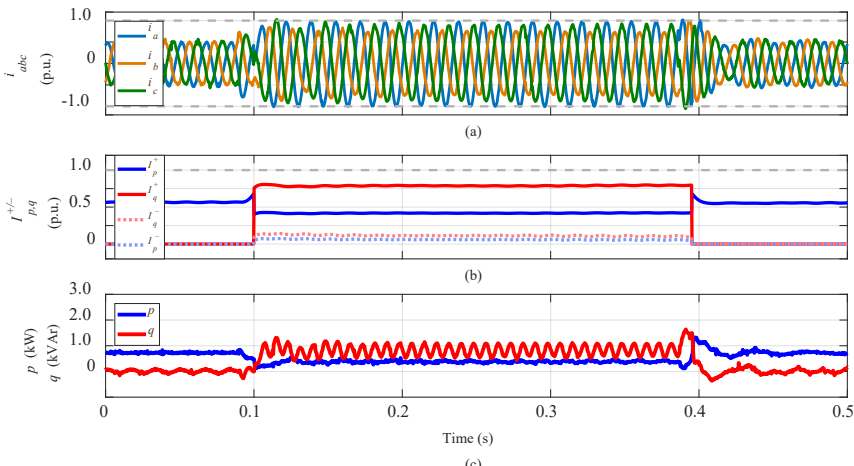

Fig. 7. Test in a mainly inductive $R L$ grid, $P_{G}=750 \mathrm{~W}$. (a) Injected phase currents. (b) Positive- and negative-sequence active and reactive currents. (c) Instantaneous powers.

oscillations. Also, $I_{q}^{+}$and $I_{q}^{-}$become different from zero to generate the reference currents for optimal voltage support. Fig. 7(c) plots the instantaneous active and reactive powers during the test. Before the sag, the inverter only delivers active power into the grid according to the power source production, that is, $750 \mathrm{~W}$. During the sag, the controller performs active power curtailment, $P \approx 300 \mathrm{~W}$, prioritizing reactive current injection. When the fault is cleared, the pre-fault power delivery is kept. As can be seen, during the sag, oscillations in instantaneous active power are zero (i.e., the objective 3 is fulfilled). In addition, reactive power oscillations appear, as predicted by (16).

It must be pointed out that if inaccurate impedance estimation is done, optimal voltage support will not be provided, although this source of error does not compromise objectives 2 and 3. Fig. 6(c) clearly shows the provided voltage support under these no optimal circumstances.

\section{Scenario 2. Mainly Inductive RL Grid-Low Active Power Production}

In this second test, the same grid impedance $Z_{g}=1.0+$ j1.885 $\Omega$ is considered, but in a low active power production scenario, $P_{G}=150 \mathrm{~W}$. As seen above, the optimal injection requires a sufficient level of power $(P \approx 300 \mathrm{~W})$ to inject the maximum current with the desired angle, see Fig. 7(c). Because the generated active power is less than the optimal value, the inverter injects all the generated active power and recalculates the amount of reactive power needed to reach the maximum current. In this case, only objectives 2 and 3 are achieved.

Fig. 8(a) shows the currents safely limited to $I_{\text {rated. }}$ In Fig. 8 (b) it can be appreciated that $I_{p}^{+}$increases slightly to maintain pre-sag injection and $I_{p}^{-}$becomes higher than zero to deliver the active power free of oscillations [objective 3 accomplished, see Fig. 8(c)]. In this case, $\theta_{i n j}=78.8^{\circ}$, near to $90^{\circ}$ since almost all the injected power is reactive. Fig. 8(d) also demonstrates that due to $\theta_{i n j} \neq \theta_{g}$, the voltage support is lower than in the optimal case.

\section{Scenario 3. Mainly Inductive Grid-High Active Power Production}

In this third scenario, the grid impedance is mainly inductive, $Z_{g}=0.1+\mathrm{j} 1.885 \Omega, \theta_{g} \approx 90^{\circ}$, and $P_{G}$ is also $750 \mathrm{~W}$. As above, the currents are safely limited to 1 p.u. [see Fig.
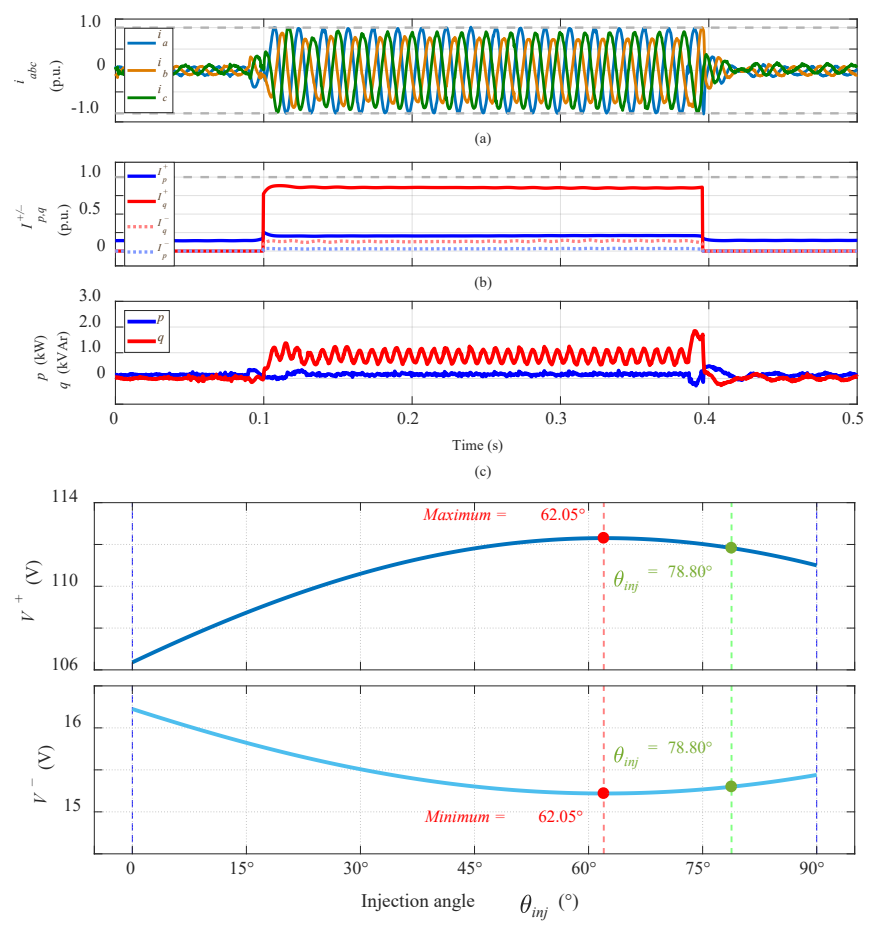

(d)

Fig. 8. Test in a mainly inductive $R L$ grid, $P_{G}=150 \mathrm{~W}$. (a) Injected phase currents. (b) Positive- and negative-sequence active and reactive currents. (c) Instantaneous powers. (d) $V^{+}$and $V^{-}$when $\theta_{\text {inj }} \neq \theta_{g}$.

9(a)]. Fig. 9(b) shows how the controller only injects $I_{q}^{+}$and $I_{q}^{-}$during the fault, $\theta_{i n j}=90^{\circ}$. The injection of $I_{p}^{+}$and $I_{p}^{-}$is discarded by the controller as its effect on the voltage support is almost negligible in this test. As can be seen in Fig. 9(c), a total active power curtailment is performed during the sag (i.e., $P=0$ and also free of oscillations). Finally, in Fig. 9(d) it can be appreciated that $V^{+}$and $V^{-}$become $111.0 \mathrm{~V}(0.71$ p.u.) and $15.44 \mathrm{~V}$ (0.1 p.u.), respectively. As expected, the maximum value of $V^{+}$and the minimum value of $V^{-}$are obtained when $\theta_{i n j}$ coincides with $\theta_{g}$.

\section{E. Scenario 4. Mainly Resistive Grid-High Active Power Production}

In the last scenario, the grid impedance is $R L$ but mainly resistive, $Z_{g}=4.0+\mathrm{j} 1.885 \Omega, \theta_{g}=25.23^{\circ}$. When using the proposed controller, the injection angle is also $\theta_{i n j}=25.23^{\circ}$. As can be seen in Fig. 10(b), the optimal control prioritizes the active power injection and, in this case, no active power curtailment is performed [see Fig. 10(c)]. Fig. 10(d) shows that the optimal voltage support is produced when $\theta_{i n j}=\theta_{g}=$ $25.23^{\circ}$.

\section{F. Discussion}

Table III presents a comprehensive experimental comparison between previous state-of-the-art controllers and the proposed one. A deep sag is programmed in the grid emulator: $V^{+}=0.55$ p.u., $V^{-}=0.075$ p.u. with a grid impedance $Z_{g}=1.0+\mathrm{j} 1.885 \Omega$. When only injecting active power through positive sequence limited to $I_{\text {rated }}(6 \mathrm{~A})$, the 

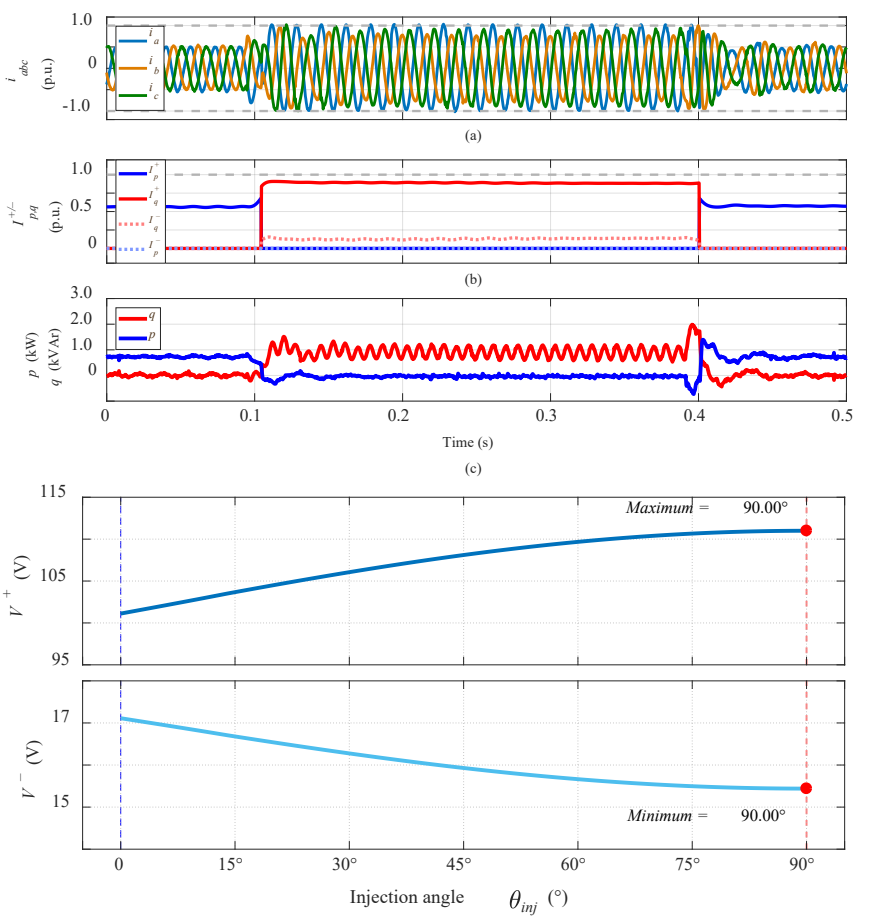

(d)

Fig. 9. Test in a pure inductive grid, $P_{G}=750 \mathrm{~W}$. (a) Injected phase currents. (b) Positive- and negative-sequence active and reactive currents. (c) Instantaneous powers. (d) $V^{+}$and $V^{-}$under impedance matching and injection angle.

maximum $P_{G}$ that can be transferred to the grid is $817 \mathrm{~W}$, with a high oscillation in active power. As can be seen, due to $R_{g} \neq$ $0 \Omega$, with this active power injection, $V^{+}$is increased.

Different techniques have been chosen to present a comprehensive comparison with the proposal. The first merit factor is to minimize active power oscillations and the second one is to maximize the value of the difference between $\mathrm{V}^{+}$ and $V^{-}$. The last objective, safe current limitation to $I_{\text {rated }}$, is common to all the chosen techniques. Also, the consideration of a complex grid impedance $(R L)$ has been chosen as a merit factor that improves the state-of-the-art knowledge.

When testing [23], the total active power that is being generated $\left(P_{G}\right)$ is injected to the grid and has been chosen to $707 \mathrm{~W}$ (lower than the maximum allowable $817 \mathrm{~W}$ ), see Table III. Thus, with [23], the active power is injected through $I_{p}^{+}$ and $I_{p}^{-}$to eliminate $\tilde{p}$. In this case, there is still some capacity to inject reactive power until $I_{\text {rated }}$ is reached. It must be pointed out that during the sag $I_{q}^{+}$and $I_{q}^{-}$are injected without following any GC requirement. Therefore, this

TABLE III

COMPARISON WITH STATE OF THE ART

\begin{tabular}{|c|c|c|c|c|c|c|c|}
\hline Technique & $R L$ & $\begin{array}{c}P \\
(\mathrm{~W})\end{array}$ & $\begin{array}{c}\tilde{p} \\
(\mathrm{~W})\end{array}$ & $\begin{array}{c}V^{+} \\
\text {(p.u.) }\end{array}$ & $\begin{array}{c}V^{-} \\
\text {(p.u.) }\end{array}$ & $\begin{array}{c}V^{+}-V^{-} \\
\text {(p.u.) }\end{array}$ & $\%$ \\
\hline Sag no $P$ & $\checkmark$ & 0 & 0 & 0.5500 & 0.0750 & 0.4750 & 0 \\
\hline Sag $I_{p}^{+}$ & $\checkmark$ & 817 & 210 & 0.5837 & 0.0750 & 0.5087 & 37 \\
\hline [8] & $x$ & 707 & 213 & 0.6226 & 0.0750 & 0.5476 & 80 \\
\hline [23] & $x$ & 707 & 0 & 0.6069 & 0.0682 & 0.5387 & 70 \\
\hline [39] & $x$ & 600 & 0 & 0.6194 & 0.0673 & 0.5521 & 85 \\
\hline$[30]$ & $\checkmark$ & 358 & 925 & 0.5944 & 0.0288 & 0.5656 & 100 \\
\hline Proposal & $\checkmark$ & 370 & 0 & 0.6252 & 0.0669 & 0.5583 & 91 \\
\hline
\end{tabular}
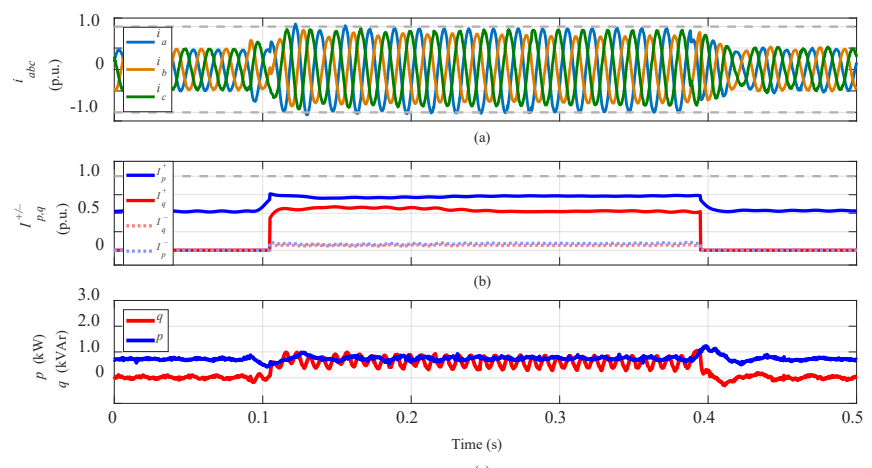

(c)

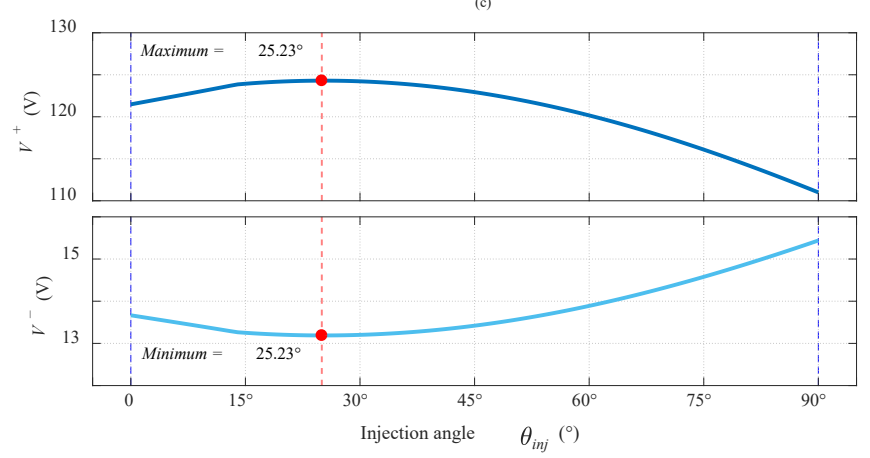

(d)

Fig. 10. Test in a mainly resistive $R L$ grid, $P_{G}=750 \mathrm{~W}$. (a) Injected phase currents. (b) Positive- and negative-sequence active and reactive currents. (c) Instantaneous powers. (d) $V^{+}$and $V^{-}$under impedance matching and injection angle.

approach is adequate for instance for grid-connected photovoltaic systems in Spain [43]. In this case, the difference between $V^{+}$and $V^{-}$nearly coincides with the basic approach (see Table III). The second evaluated reference is [8], which stipulates the grid code RCI requirements for wind farms in Spain. In this case, $P_{G}$ is equal to $707 \mathrm{~W}$ (as above), but this $\mathrm{GC}$ requires active power curtailment to ensure a minimum ratio between reactive and total current $I_{q}^{+} / I_{T}$, being $I_{T}=$ $I_{\text {rated }}$ in the experimental setup. Because of that, only positivesequence currents are injected, $\tilde{p}$ is not zero. As a positive feature, the sequence voltage increment $\left(V^{+}-V^{-}=0.5476\right.$ p.u. $)$ is better than in [23].

In [39], the Spanish GC for wind farms is adapted to avoid oscillations in $p$ (i.e., active and reactive currents are injected through both sequences), with the drawback of increasing the power curtailment ( $P$ reduced to $600 \mathrm{~W}$ ); however, an interesting increase in $V^{+}-V^{-}=0.5521$ p.u. is appreciated. Note that none of these bibliographical references takes into account theoretically an $R L$ grid. In contrast, reference [30], develops an optimized scheme to maximize $V^{+}-V^{-}$but with the strong drawback of injecting only $P=358 \mathrm{~W}$ with a nonacceptable ripple of $925 \mathrm{~W}$. As a conclusion, the proposed scheme is free of active power oscillations and, as its main advantage, maximizes $V^{+}-V^{-}$in contrast to [8], [23], [39]. Thus a percent column has been added into Table III to clearly observe the improvement when using the proposal, taking the best value of $V^{+}-V^{-}$as $100 \%$ (when using [30]). As can be seen, the proposal is near the optimum with $91 \%$ of improvement. 
As a final remark, note that the existing voltage support techniques can be adapted following the approach presented in this study (i.e., optimizing the voltage support by modifying the injection angle according to the grid impedance angle). In this sense, the proposed optimization technique can be viewed as a tool for improving the performance of previous control schemes.

\section{CONCLUSION AND FUTURE WORK}

An optimal voltage-support control strategy for three-phase three-wire VSIs connected to $R L$ grids during voltage sags is presented in this paper. This control strategy removes oscillations in the active power and reduces the voltage imbalance by maximizing and minimizing the amplitudes of the positive- and negative-sequence voltages, respectively. Also, this proposal makes possible a safe inverter operation by confining the maximum current amplitudes to the rated value. Experimental and numerical validations are in accordance with the theoretical predictions.

As demonstrated experimentally, the benefits of the proposed control scheme are based on the knowledge of the grid impedance angle $\theta_{g}$, a value that must be calculated using online impedance estimators or through the knowledge of the nearby elements close to the facility.

This work has been shown that multiple control objectives can be fulfilled simultaneously to achieve optimum voltage support in $R L$ grids during voltage sags. Future work will extend the application of this strategy to the operation of gridconnected microgrids and multiple inverters in a distributed generation scenario. The analysis of interactions among multiple inverters is a challenging topic for future research.

\section{REFERENCES}

[1] F. Blaabjerg, R. Teodorescu, M. Liserre, and A. V. Timbus, "Overview of control and grid synchronization for distributed power generation systems," IEEE Trans. Ind. Electron., vol. 53, no. 5, pp. 1398-1409, Oct. 2006.

[2] M. Tsili and S. Papathanassiou, "A review of grid code technical requirements for wind farms," IET Renew. Power Gener., vol. 3, no. 3, p. 308, 2009.

[3] M. Altin, O. Goksu, R. Teodorescu, P. Rodriguez, B.-B. Jensen, and L. Helle, "Overview of recent grid codes for wind power integration," in 2010 12th International Conference on Optimization of Electrical and Electronic Equipment, 2010, pp. 1152-1160.

[4] Y. Yang, P. Enjeti, F. Blaabjerg, and H. Wang, "Wide-scale adoption of photovoltaic energy: Grid code modifications are explored in the distribution grid," IEEE Ind. Appl. Mag., vol. 21, no. 5, pp. 21-31, Sep. 2015.

[5] "Waveform characteristics of voltage sags: Statistical analysis. TR112692," EPRI, Palo Alto, CA, 1999.

[6] "Network code for requirements for grid connection applicable to all generators," ENTSO-E, Brussels, Belgium, 2013.

[7] "Grid code for high and extra high voltage," E.ON Netz GmbH, Bayreuth, Germany, 2006.

[8] "P.O. 12.3. Response requirements against voltage dips in wind installations," Red Eléctrica de España (REE), Madrid, España, 2006.

[9] "Portaria n. ${ }^{\circ}$ 596/2010. Regulamento da rede de transporte," A Entidade Reguladora dos Serviços Energéticos, Lisboa, Portugal, 2010.

[10] "Distribution code approved by CER," Distribution System Operator ESB Networks Limited, Dublin, Ireland, 2016.

[11] J. L. Blackburn and T. J. Domin, "Fundamental units: Per unit and percent values," in Protective Relaying: Principles and Applications, 3rd ed., Boca Raton, FL, USA: CRC Press, 2006.

[12] J. L. Blackburn and T. J. Domin, "Symmetrical components: A review," in Protective Relaying: Principles and Applications, 3rd ed., Boca Raton, FL, USA: CRC Press, 2006.
[13] S. Alepuz et al., "Control strategies based on symmetrical components for grid-connected converters under voltage dips," IEEE Trans. Ind. Electron., vol. 56, no. 6, pp. 2162-2173, Jun. 2009.

[14] A. Milicua, G. Abad, and M. A. Rodriguez Vidal, "Online reference limitation method of shunt-connected converters to the grid to avoid exceeding voltage and current limits under unbalanced operation-Part I: Theory," IEEE Trans. Energy Convers., vol. 30, no. 3, pp. 852-863, Sep. 2015.

[15] P. Rodriguez, G. Medeiros, A. Luna, M. C. Cavalcanti, and R. Teodorescu, "Safe current injection strategies for a STATCOM under asymmetrical grid faults," in 2010 IEEE Energy Conversion Congress and Exposition, 2010, pp. 3929-3935.

[16] P. Rodriguez, A. Luna, J. R. Hermoso, I. Etxeberria-Otadui, R. Teodorescu, and F. Blaabjerg, "Current control method for distributed generation power generation plants under grid fault conditions," in IECON 2011 - 37th Annual Conference of the IEEE Industrial Electronics Society, 2011, pp. 1262-1269.

[17] J. A. Suul, A. Luna, P. Rodríguez, and T. Undeland, "Virtual-fluxbased voltage-sensor-less power control for unbalanced grid conditions," IEEE Trans. Power Electron., vol. 27, no. 9, pp. 40714087, Sep. 2012.

[18] A. Camacho, M. Castilla, J. Miret, J. C. Vasquez, and E. AlarconGallo, "Flexible voltage support control for three-phase distributed generation inverters under grid fault," IEEE Trans. Ind. Electron., vol. 60, no. 4, pp. 1429-1441, Apr. 2013.

[19] J. Miret, A. Camacho, M. Castilla, L. G. de Vicuña, and J. Matas, "Control scheme with voltage support capability for distributed generation inverters under voltage sags," IEEE Trans. Power Electron., vol. 28, no. 11, pp. 5252-5262, Nov. 2013.

[20] A. Camacho, M. Castilla, J. Miret, R. Guzman, and A. Borrell, "Reactive power control for distributed generation power plants to comply with voltage limits during grid faults," IEEE Trans. Power Electron., vol. 29, no. 11, pp. 6224-6234, Nov. 2014.

[21] J. Miret, M. Castilla, A. Camacho, L. G. de Vicuña, and J. Matas, "Control scheme for photovoltaic three-phase inverters to minimize peak currents during unbalanced grid-voltage sags," IEEE Trans. Power Electron., vol. 27, no. 10, pp. 4262-4271, Oct. 2012.

[22] C.-T. Lee, C.-W. Hsu, and P.-T. Cheng, "A low-voltage ride-through technique for grid-connected converters of distributed energy resources," IEEE Trans. Ind. Appl., vol. 47, no. 4, pp. 1821-1832, Jul. 2011.

[23] J. L. Sosa, M. Castilla, J. Miret, J. Matas, and Y. A. Al-Turki, "Control strategy to maximize the power capability of PV three-phase inverters during voltage sags," IEEE Trans. Power Electron., vol. 31, no. 4, pp. 3314-3323, Apr. 2016.

[24] C. Tang, Y.-T. Chen, and Y. Chen, "PV power system with multi-mode operation and low-voltage ride-through capability," IEEE Trans. Ind. Electron., vol. 62, no. 12, pp. 7524-7533, Dec. 2015.

[25] H.-C. Chen, C.-T. Lee, P.-T. Cheng, R. Teodorescu, and F. Blaabjerg, "A low-voltage ride-through technique for grid-connected converters with reduced power transistors stress," IEEE Trans. Power Electron., vol. 31, no. 12, pp. 8562-8571, 2016.

[26] X. Guo, X. Zhang, B. Wang, W. Wu, and J. M. Guerrero, "Asymmetrical grid fault ride-through strategy of three-phase gridconnected inverter considering network impedance impact in lowvoltage grid," IEEE Trans. Power Electron., vol. 29, no. 3, pp. 10641068, Mar. 2014.

[27] A. Camacho, M. Castilla, J. Miret, P. Marti, and M. Velasco, "Maximizing positive sequence voltage support in inductive-resistive grids for distributed generation inverters during voltage sags," in IECON 2016 - 42nd Annual Conference of the IEEE Industrial Electronics Society, 2016, pp. 2343-2348.

[28] M. M. Shabestary and Y. A.-R. I. Mohamed, "Advanced voltage support and active power flow control in grid-connected converters under unbalanced conditions," IEEE Trans. Power Electron., vol. 33, no. 2, pp. 1855-1864, Feb. 2018.

[29] A. Camacho, M. Castilla, J. Miret, L. García de Vicuña, and M. A. Garnica López, "Control strategy for distribution generation inverters to maximize the voltage support in the lowest phase during voltage sags," IEEE Trans. Ind. Electron., vol. 65, no. 3, pp. 2346-2355, Mar. 2018.

[30] A. Camacho, M. Castilla, J. Miret, L. G. de Vicuna, and R. Guzman, "Positive and negative sequence control strategies to maximize the voltage support in resistive-inductive grids during grid faults," IEEE 
Trans. Power Electron., vol. 33, no. 6, pp. 5362-5373, Jun. 2018.

[31] R. Teodorescu, M. Liserre, and P. Rodríguez, "Grid converter control for WTS," in Grid Converters for Photovoltaic and Wind Power Systems, Chichester, UK: John Wiley \& Sons, Ltd, 2010, pp. 205-236.

[32] A. Milicua, G. Abad, and M. A. Rodriguez Vidal, "Online reference limitation method of shunt-connected converters to the grid to avoid exceeding voltage and current limits under unbalanced operation-Part II: Validation," IEEE Trans. Energy Convers., vol. 30, no. 3, pp. 864 873, Sep. 2015.

[33] M. A. Hossain, H. R. Pota, A. M. O. Haruni, and M. J. Hossain, "DClink voltage regulation of inverters to enhance microgrid stability during network contingencies," Electr. Power Syst. Res., vol. 147, pp. 233-244, Jun. 2017.

[34] J. Liu, L. Zhou, X. Yu, B. Li, and C. Zheng, "Design and analysis of an $L C L$ circuit-based three-phase grid-connected inverter," IET Power Electron., vol. 10, no. 2, pp. 232-239, Feb. 2017.

[35] L. Asiminoaei, R. Teodorescu, F. Blaabjerg, and U. Borup, "Implementation and test of an online embedded grid impedance estimation technique for PV inverters," IEEE Trans. Ind. Electron., vol. 52, no. 4, pp. 1136-1144, Aug. 2005.

[36] A. Vidal et al., "A Method for identification of the equivalent inductance and resistance in the plant model of current-controlled gridtied converters," IEEE Trans. Power Electron., vol. 30, no. 12, pp. 7245-7261, Dec. 2015.

[37] R. Teodorescu, M. Liserre, and P. Rodríguez, "Grid synchronization in three-phase power converters," in Grid Converters for Photovoltaic and Wind Power Systems, Chichester, UK: John Wiley \& Sons, Ltd, 2010, pp. 169-204.

[38] IEEE Recommended Practice for Electric Power Distribution for Industrial Plants. IEEE Std 141 ${ }^{\mathrm{TM}}-1993$ (R1999), 1994.

[39] M. A. Garnica Lopez, J. L. Garcia de Vicuna, J. Miret, M. Castilla, and R. Guzman, "Control strategy for grid-connected three-phase inverters during voltage sags to meet grid codes and to maximize power delivery capability," IEEE Trans. Power Electron., vol. 33, no. 11, pp. 93609374, Nov. 2018.

[40] F. J. Rodriguez, E. Bueno, M. Aredes, L. G. B. Rolim, F. A. S. Neves, and M. C. Cavalcanti, "Discrete-time implementation of second order generalized integrators for grid converters," in 2008 34th Annual Conference of IEEE Industrial Electronics, 2008, no. 1, pp. 176-181.

[41] A. Yazdani and R. Iravani, "Space phasors and two-dimensional frames," in Voltage-Sourced Converters in Power Systems, Hoboken, NJ, USA: John Wiley \& Sons, Inc., 2010, pp. 69-114.

[42] D. N. Zmood, D. G. Holmes, and G. H. Bode, "Frequency-domain analysis of three-phase linear current regulators," IEEE Trans. Ind. Appl., vol. 37, no. 2, pp. 601-610, 2001.

[43] B.-I. Craciun, T. Kerekes, D. Sera, and R. Teodorescu, "Overview of recent grid codes for PV power integration," in 2012 13th International Conference on Optimization of Electrical and Electronic Equipment (OPTIM), 2012, pp. 959-965.

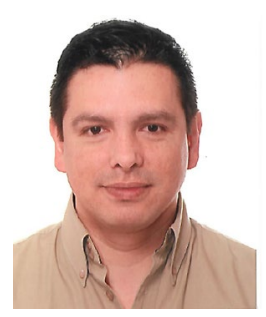

Miguel Garnica was born in San Juan de Pasto, Nariño, Colombia, on December 1973. $\mathrm{He}$ received the B.S. in Naval Engineering (Electronics) from the Escuela Naval de Cadetes "Almirante Padilla" (ENAP), Cartagena de Indias, D. T. y C., Bolívar, Colombia, in 2002, the M.S. degree in Electronic Engineering from the Universitat de Barcelona (UB), Barcelona, Spain, in 2012, and the Ph.D. degree in Electronic Engineering from the Universitat Politècnica de Catalunya (UPC), Barcelona, Spain, on January 2019.

$\mathrm{He}$ is currently a researcher and professor of the Grupo de Investigación en Comunicación, Control y Diseño Naval (GICCDN), ENAP. His research interests include power electronics, control systems, and renewable energy systems.

Dr. Garnica is Captain of the Armada de Colombia (ARC) and presently serves as Director of the Centro de Investigaciones Científicas de la Escuela Naval de Cadetes "Almirante Padilla" (CICEN).

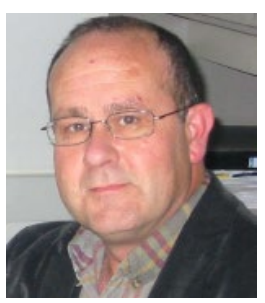

Luis García de Vicuña received the M.S. and Ph.D. degrees in Telecommunication Engineering from the Technical University of Catalonia, Barcelona, Spain, in 1980 and 1990, respectively, and the Ph.D. degree in Electrical Engineering from the Paul Sabatier University, Toulouse, France, in 1992.

$\mathrm{He}$ is currently a Full Professor with the Department of Electronic Engineering, Technical University of Catalonia, where he teaches courses on Power Electronics. His research interests include power electronics modeling, simulation and control, active power filtering, and high power-factor ac/dc conversion.

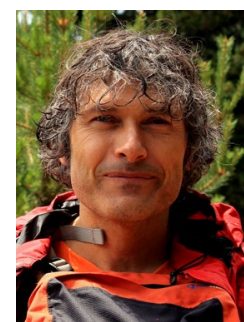

Jaume Miret (M'98) received the B.S. degree in Telecommunications, M.S. degree in Electronics, and Ph.D. degree in Electronics from the Universitat Politècnica de Catalunya, Barcelona, Spain, in 1992, 1999, and 2005, respectively.

From 1993 to 2011, he was an Assistant Professor in the Department of Electronic Engineering, Universitat Politècnica de Catalunya, Spain. Since 2011, he has been an Associate Professor in the Universitat Politècnica de Catalunya, where he teaches courses on Digital Design and Circuit Theory. His research interests include dc-to-ac converters, active power filters, and digital control.

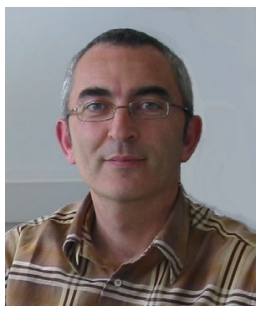

Miguel Castilla received the B.S., M.S., and Ph.D. degrees in Telecommunication Engineering from the Technical University of Catalonia, Barcelona, Spain, in 1988, 1995, and 1998, respectively.

Since 2002, he has been an Associate Professor and is currently a Full Professor in the Department of Electronic Engineering, Technical University of Catalonia, where he teaches courses on Analog Circuits and Power Electronics. His research interests are in the areas of power electronics, nonlinear control, and renewable energy systems.

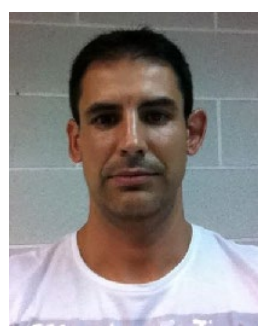

Ramón Guzmán received the B.S., the M.S., and the Ph.D. degrees in Telecommunications Engineering from the Technical University of Catalonia, Barcelona, Spain, in 1999, 2004 and 2016, respectively.

$\mathrm{He}$ is currently an Associate Professor with the Department of Automatic Control in the Technical University of Catalonia. His research interests include nonlinear and adaptive control for three-phase power converters. 